\title{
Correction to: People with diabetes do not learn and recall their diabetes foot education: a cohort study
}

\author{
Julia Yuncken ${ }^{1}$ - Cylie M. Williams ${ }^{1,2} \cdot$ Renerus J. Stolwyk ${ }^{3,4,5} \cdot$ Terry P. Haines ${ }^{6,7}$
}

Published online: 30 November 2018

(c) Springer Science+Business Media, LLC, part of Springer Nature 2018

\section{Correction to: Endocrine 2018}

https://doi.org/10.1007/s12020-018-1714-1

The original version of this article unfortunately contained an mistake in country name in all the affiliations. The

county name was inadvertently published as USA, it should be Australia instead. The affiliations are corrected in this erratum.
The original article can be found online at https://doi.org/10.1007/ s12020-018-1714-1.

\section{Julia Yuncken}

Julia.Yuncken@monash.edu

1 Peninsula Health, Community Health, PO Box 52, Frankston, VIC 3199, Australia

2 Department of Physiotherapy, Monash University, McMahon's Rd, Frankston, VIC 3199, Australia

3 School of Psychological Sciences, Monash University, Clayton, Australia
4 Monash Institute of Cognitive and Clinical Neurosciences, Clayton, Australia

5 Monash-Epworth Rehabilitation Research Centre, Richmond, Australia

6 Monash Health, Allied Health Research Unit, Kingston Centre, Warrigal Rd, Cheltenham, VIC 3192, Australia

7 Department of School of Primary and Allied Health Care, Monash University, McMahon's Rd, Frankston, VIC 3199, Australia 